\title{
Proceduralization, transfer of training and retention of knowledge as a result of output practice
}

\author{
Mehrnoosh, Fakharzadeh $\bowtie$ \\ University of Isfahan, Iran (mfakharzade@shbu.ac.ir) \\ Manijah, Youhanaee \\ University of Isfahan, Iran (youhanaee_m@hotmail.com) \\ Daryoush, Nejadansari \\ University of Isfahan, Iran (ansari@fgn.ui.ac.ir)
}

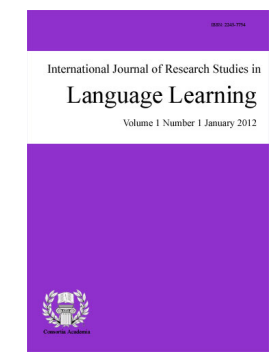

ISSN: 2243-7754 Online ISSN: 2243-7762

OPEN ACCESS

\section{Abstract}

This study investigated the effect of output practice on the proceduralization, transfer and retention of knowledge on English modals, adopting Anderson's ACT-R model of skill acquisition. A pretest posttest and delayed posttest design was used where the procedural knowledge on production skill was specifically operationalized through the groups' performance on Dual Task Timed Completion Test and transfer of training was measures through a Dual Task Timed Grammaticality Judgment Test. Two intact classes of intermediate EFL learners were randomly assigned to treatment and control groups. The output group $(\mathrm{n}=$ 27) received explicit grammar instruction, a combination of three output tasks including dictogloss, individual text reconstruction, and corrected-close translation, and feedback. The control group $(n=25)$ were just exposed to the identical texts trough listening and reading tasks followed by some questions irrelevant to the target structure. Results showed that on the posttest, three days after the last treatment session, the output group outperformed the control group in both measures of procedural knowledge and transfer of knowledge. As for retention, forty days later, the output group's performance was still significantly better than the pretest. This group also succeeded in retaining its outperformance on both measures of procedural knowledge and transfer of knowledge delayed posttest. The results may help language teachers design more effective activities for the learners considering the institutional constraints.

Keywords: ACT-R skill learning theory; Procedural knowledge; transfer of training; retention 


\section{Proceduralization, transfer of training and retention of knowledge as a result of output practice}

\section{Introduction}

Educational programs strive to achieve three goals of teaching: acquisition, transfer and retention of knowledge and skill. While acquisition is an aim considered and assessed during the training program or almost immediately after the final sessions thereof, transfer and retention relate to post-training performance. Transfer of knowledge or skill involves the ability of learners to generalize what they have acquired to related and altered contexts; retention on the other hand, refers to long-term maintenance of performance level (Schmidt and Bjork, 1992).

One currently popular approach to acquisition, which addresses transfer as well as retention, is skill acquisition theory. Anderson's skill acquisition theory, also known as ACT (Adaptive Control of Thought), with its goal to provide explanation for various aspects of human cognition, has been updated until last few years (Anderson, Fincham, \& Douglass, 1997; Anderson \& Shunn, 2000) yet, in all different models practice plays a focal role. The following systems are the basic architecture of cognition in this theory: the perceptual-motor system, the goal system, the declarative memory and finally the procedural memory. The components which have been received lots of attention from educational psychologists have been the declarative and the procedural memory, sine these two modules are involved when the function of practice is the focal point (Serrano, and Munoz 2007).

Declarative knowledge is added into the memory through chunks and is activated and subsequently acquires strength as a result of frequent use, i.e. practice. Proceduralization takes place when declarative knowledge is transformed into procedures, production rules, for performing a skill. Production rules also require practice to acquire activation and strength. Practice at this stage results in automatization of skill (Anderson, 1993).

Another issue which surrounds the duality of knowledge in ACT models is skill-specificity. The skill-specificity issue is probably the one that has drawn the most attention in applied linguistics lately (Dekeyser, Salaberry, Robinson, \& Harrington, 2002; Izumi, 2002, 2003; Muranoi, 2007; Qin, 2008). The practice effect is said to be specific since after the initial practice of declarative knowledge, learners incorporate the knowledge into behavioral routines which are very specific rules and can be used fast with low rate of error (Dekeyser, 2007). The production rules that were created at the second phase of skill acquisition keep fine-tuning so that they become inflexible so much so that even a slight change in the condition or parameters of practice task might result in failure in performing on post-training tests (Schmidt and Bjork, 1992). However, skill-specificity is most probably the result of a large amount of practice and prior to automatization of skill there is no way to guarantee that it is speeded availability of learners' declarative knowledge resources or production rules which have been created and fine-tuned to that specific practice task. Yet, the extent to which the acquired knowledge can be generalized, as a result of instruction and practice, to other contexts, seems to be of high importance. This phenomenon, known as" Transfer of Learning" refers to how previous leaning influences current and future learning or performance, and how past or current leaning is applied to similar novel situations (Haskell, 2001, Speelman and Kirsner, 2005).

Anderson's ACT models have also greatly relevant discussions on the role of input and output in that they put the emphasis on the relationship between practice type and the transitional change of knowledge. Ellis (1992, 1993) and VanPatten $(1996,2003)$ take the view that input practice leads to acquisition, but output practice merely serves to improve fluency. On the other hand, studies such as those by Dekeyser (1997), Dekeyser and Sokalski (1996), and Izumi (2002) clearly show a partial lack of transfer between receptive and productive skills (skill-specificity) at the level of proceduralized knowledge but not declarative knowledge. 
Proceduralization, transfer of training and retention of knowledge as a result of output practice

Reinders (2009) investigated the effects of three types of production activities on uptake, learners' correct suppliance of the target structure during the treatment, and acquisition, improved performance on a timed and an untimed grammaticality judgment test, of English negative adverbs. The three production activities included a dictation, an individual reconstruction and a collaborative reconstruction activity. It was found that all three activities resulted in uptake, with the collaborative reconstruction and the dictation activities resulting in greater uptake than the individual reconstruction activity. The tasks had an effect on acquisition of grammatical items only. There was no difference between the three tasks on acquisition. It was concluded that a production activity can lead to increased uptake, but not to increased acquisition. For logistic reasons, however, the number of participants in each group was about 15 and the treatment lasted for one week, moreover, there was no control group.

In comparison to other areas related to ACT model and its contribution to SLA, transfer of learning has remained less touched. Even those researchers, who have endeavored to find answers to transfer-of-knowledgequestions, came up with controversial conclusions. Apart from Dekeyser (1997, 2007), who believes in skill-specificity of knowledge, and Van Patten (1996, 2003), and Van Patten and Uludag (2011)who views comprehension activities as sufficient for taking care of both comprehension and production skills, Qin (2008) tried the effect of output and input practice, and concluded that both groups improved in both skills.

Nagata (1998a, 1998b) investigated the effect of computer-assisted production practice and comprehension practice in acquisition of Japanese honorifics and nominal modifiers. The study took four one-hour sessions over a course of eight days. The post tests were administered two days and the delayed posttests 6 week after the experiment. The results indicated that output computerized practice was more effective than input computerized practice for production and equally for comprehension of both structures. Although the author's focus was not on the knowledge transfer, the results revealed the advantages of output tasks in this regard. However, the results of computer assisted studies cannot be blindly generalized to the contexts where the language teachers have limited access to technological facilities.

Although the general assumption is that people have different degrees of aptitude to perform specific skills, the influence of practice has been emphasized by some authors. Eriksson, Krampe and Tesch-Romer (1993), for instance, claim that it is years of effortful, deliberate practice, that distinguishes experts from novices. Yet, in a foreign language context, like Iran, language learners usually do not have the opportunity to be immersed for a long time in a rich target language environment. Rather, they have limited language input. That is why parallel to cognitive and educational psychologists second language acquisition researchers are looking for optimal ways to deal with the insufficient time and opportunities to introduce a large amount of practice to learners, and have made attempts to manipulate one or more variables in relation to practice tasks, such as scheduling of practice, its type and last but surely not least its variety.

Despite large body of data supporting the effect of different practice tasks with certain characteristics on acquiring grammatical structures, research in this area suffers from some methodological shortcomings. First research under laboratory settings is difficult to have implications for ecologically realistic conditions. Most of the studies which addressed the effect of practice type on the acquisition of linguistic elements sufficed with a relatively short period of practice phase. Even those studies within the skill- acquisition strand, have failed to provide practice for a relatively long time to allow the declarative knowledge to become automatized. Literature shows that the maximum time allocated for practice was 16 hours (Dekeyser, 2007).

Even fewer studies have attempted to investigate if the skill-specificity is apt to be surmounted by intentional integration or variation of tasks. On the other hand, in spite of having a relatively rich literature on how different tasks might affect language acquisition, there is not much consensus, however, as to the nature, amount, and type of tasks to be used as practice. Moreover, most of the studies use short retention period, for example one week, 10 days or three weeks at most. Short retention time might make the implementation and generalization of the result troublesome if we consider the conclusion by Driskell, Willis, and Cooper (1992) that 
Mehrnoosh, F., Manijah, Y., \& Daryoush, N.

"for a cognitive task that has been leant, retention tends to dissipate after 5 to 6 weeks. This time span seems so long that few educators would consider of any practical value" (p: 771).

Aiming to contribute to filling the gap in empirical research on providing declarative knowledge as conducive (Dekeyser, 2009) to the development of proceduralized grammatical knowledge, the present study intended to examine the effect of form-focused practice tasks when the metalinguistic information on linguistic targets is presented and accompanied by a variety of form-focused production tasks to establish proceduralization. The study came up with implications for using tasks in EFL classrooms to improve accuracy and fluency of language learners.

\section{Research questions}

The present study investigated the following research questions:

1. Does output practice task result in acquisition of proceduralization of procedural knowledge on English modal verbs?

2. Does output practice task result in transfer of procedural knowledge from production to comprehension context?

3. Does output practice task lead into retention of modal procedural knowledge?

\section{Method}

\subsection{Design}

For the design of the current study a pretest/posttest/delayed posttest intact group design was employed to investigate the effectiveness of output form-focused tasks as practice on the acquisition, retention and transfer of procedural knowledge on English modals.

\subsection{Context and participants of the study}

The study was conducted at university of Sheikhbahaee in Isfahan, Iran. Two intact classes were involved, making this a sample of convenient. Due to institutional constraints, it was not possible to assign the students randomly to treatment and control groups. At the time of the study all the participants had just enrolled in the second semester. All the participants were, then, freshmen studying English literature, translation or TEFL. They were between 18- 25 years of age (average 21), and shared basic demographic characteristics, such as L1, age and field of study.

Since the study addressed the Intermediate population of foreign language learners, the researchers were required to ensure that the participants were homogeneous. To this end, a 60 item Oxford Placement Test, OPT (2001) was administered in the intact classes. Based on the OPT score classification (20-28 elementary, 34-43 intermediate, 50-55- advanced), out of initially 60 participants in two classes 5 were elementary and 2 were advanced. The remaining 52 intermediate participants' score ranged from 34 to 43 . Being an intact study, therefore, the elementary and advanced learners also received the treatments. In all the processes of the study the data related to advanced and elementary level learners were excluded from the final results. The total number of participants involved in the study was, then, 52. They were both male $(\mathrm{N}=17)$ and female $(\mathrm{N}=35)$. The numbers of participants in the control and output groups were 25 and 27 respectively.

Apart from the intermediate level participants 6 English native speakers participated in the study. They were both male ( $\mathrm{N}=4)$ and female $(\mathrm{N}=2)$ aged between 32- 45, and living in, England, Australia and Canada. The native speakers were all educated at the levels ranging from bachelor up to the $\mathrm{PhD}$ degrees in different 
Proceduralization, transfer of training and retention of knowledge as a result of output practice

academic majors. Their performance on the tests helped the researchers to modify some items which seemed complicated, ambiguous or difficult for the participants to process. The time limit (see section 3.5) of tests was also decided based on the native speakers' performance.

\subsection{Target structure}

The target structure in the present study was English modal verbs. A brief review of literature showed that English modals are linguistic features which are cross-linguistically problematic to EFL learners; in terms of developmental properties of L2 acquisition (Pienemann, 1982) modals are acquired early. Although English modal verbs are frequently used in oral and written text, they are non-salient features in that, they tend to be unstressed, hence difficult to notice in the discourse, and their form-meaning mapping is also problematic (Ellis, 2009).

\subsection{Instructional materials}

The input tasks which served the goal of the present study were:

1. Dictogloss: a structure-based production task, proposed by Wajnryb (1990). It required the use of a short text that was selected or devised to have a structural focuses, modals and subjunctions. The texts were read at normal speed, two times, sentence by sentence, while the learners noted down key words and phrases. The learners then worked personally to reconstruct it as accurately as possible and receive feedback from the researcher particularly on the target structures.(See Appendix A for a sample of this task).

2. Text-reconstruction task: a structure-based production task proposed by Izumi and Bigelow (2000). It required the participants to read a short written passage that was seeded with the target structure and to underline the parts which they felt were important for subsequent reconstruction. The passages were then collected and the participants were asked to reconstruct them as accurately as possible. They were then given the chance to compare what they produced with the original text. (See Appendix A for a sample of this task).

3. Corrected close translation (L1-L2): a form-focused task proposed by Cook (2010). It required learners to produce translation in which they were to keep as close as possible to the original. The learners then found the opportunity to compare their text with the original one3. (See Appendix A for a sample of this task).

\subsection{Testing materials}

Since in the practice context the participants received production tasks, the effect of practice on acquisition of productive procedural knowledge was operationalized through measuring subjects' performance on a production test: Dual Task Timed Completion Test (DTCOMT). Transfer of knowledge was measured through their performance on a comprehension test: Dual Task Timed Grammaticality Judgment Test (DTGJT). Apart from the timed and task duality features, both of the tests bore structurally irrelevant items to be answered. Timedness and inclusion of irrelevant items were decided after Ellis (2009) proposing Time and Focus of attention as two criteria, among others, which are basic to operationalizing the measurement of different types of knowledge, implicit/procedural and explicit/declarative. Dual task was adopted from DeKeyser (1997), for measuring procedural knowledge which partly guarantees that the learners are deprived of the opportunity to draw upon their controlled processing. The tests involve the learners' being pressured to perform a task online as opposed to when they have an opportunity to plan their response carefully. Operationally, this involves distinguishing tasks that make significant demands on learners' short-term memories and those that lie comfortably within their L2 processing capacity. In other word, duality of task and timed criterion are to operationalize the degree to which the knowledge has been proceduralized.

The DTGJ was a pen and paper test consisting of 84 items, grammatical and ungrammatical items. 28 of the sentences were related to the target structure. The remaining 56 items were irrelevant to the target structure so as 
Mehrnoosh, F., Manijah, Y., \& Daryoush, N.

to minimize the items being form focused. To lower the probability of the test instruction interference with their performance they were given freedom to indicate grammaticality or ungrammaticality of the items in a way they were convenient with. They were asked to underline the wrong part of ungrammatical items. The number of irreverent items was decided to be about two times of the related items, by consulting the related literature. The participants were also asked to write the number of beep sound in front of each item, while answering the tests.

The time limit for each sentence was established on the basis of native English speakers' average response time, to which was added an additional $20 \%$ of the time to allow for the slower processing speed of L2 learners (Ellis 2009). The mean time spent by the native speakers to answer all the items of DTGJT was 17.5 minutes. 3.5 minutes was added to this figure $(17.5 * 0.2=3.5)$. The total time of answering the items was 21 minutes. The average time allocation for each item was, then, about 15 seconds. However, the items were not of equal length, therefore, for short items, they were given about 10 seconds to read and mark them as grammatical/ungrammatical. For longer items they had about 20 seconds to mark the sentences.

The DTCOMT was a 42-item test. It intended to measure production of the target linguistic feature. There were 14 items related to the target structure. The remaining 28 items were irrelevant so that the participants' attention would be deviated from the target structure. The number of irreverent items was decided to be about two times of the related items, by consulting the related literature. The learners were also challenged with the same simultaneous task of beep sound. The time allocation established based on the native speakers' performance was 15 seconds, for shorter items, and 25 seconds for the longer ones.

In both tests, apart from being asked to read the instruction of the test, on receiving the papers, the participants were also orally explained about what they were expected to do. On the first page, the test included just some example items and five irrelevant fillers. The inclusion of only irrelevant items on the first page prevented the learners, who received the tests earlier, to start answering the items related to target structures. The participants were given the allocated time for each item by the researcher asking them to move to the next item as soon as the time for answering one item was up. They were also to write the number of beep sounds while answering each item. In the completion test the irrelevant items tested various aspects related to verbs of the sentences. This was done since the instruction of the test could not indicate the focuses of the measure. Hence, the participants were required to provide the appropriate form of the verb plus another linguistic item where necessary. For example, some verbs of irrelevant items requited the use of preposition; others needed to be presented with appropriate form of to be or to have and still others depended on providing the appropriate passive structure.

Reliability of the measures, were calculated, using internal consistency of the items in each test over three phases of testing. Cronbach's alpha values for the DTGJT in the pre, post and delayed posttest were 0.63, 0.79, and 0.81 respectively. The values for the DTCOMT were $0.6,0.8$, and 0.89 , in pre, post and delayed posttests, respectively.

\subsection{Procedures}

A week prior to the administration of the pretests the participants in both groups received a 60 item Oxford Placement Test, OPT (2001). Participants in both groups completed the pretests a week before they received explicit instruction on the target structure. Those students, who answered above $50 \%$ of the tests items correct, were excluded from the study. The classes, then, were randomly assigned to one experimental and one control group. Both classes were taught by the same teacher who was also one of the researchers.

In the third week of the study the treatment group received the explicit instruction on the target structure, after that, they received their packet of form-focused tasks which lasted for 12 weeks. The post- tests were administered the next session. And the delayed post tests were received six weeks after the administration of the posttests. Table 1 summarizes the procedure of the study. 
Table 1

Procedure of the study

Week 1: OPT ( two groups)

Week 2-Pretests (two groups)

Week 3- Explicit instruction Output Group)

\begin{tabular}{l|l} 
Week 4 to15- Output Group & Dictogloss, Text reconstruction, Corrected close translation \\
\hline
\end{tabular}

Week 4 to 15- Control Croup Reading comprehension, listening comprehension

Week 15- Posttests ( Two groups)

Week 21- Delayed posttests ( Two groups)

As for the explicit instruction the present research adopted the preemptive explicit focus- on- form for instruction of grammar (Ellis, 2007).This type of explicit form-focused instruction is realized by means of metalinguistic explanation, which, in the present study, was received by the participants on a handout and explained by the teacher in English and Persian. The explicit instruction took place over one whole session of 90 minutes. The task sessions, 45 minutes each, were held two times, a week and started when the explicit instruction was completed.

The control were exposed to the same texts, used for the experimental group, yet the questions following texts were comprehension questions and that did not require their focus on the target structure.

One version of the tests was used over all three testing phases, pre, post and delayed posttests. However, the order of the items of the tests was different for each test administration. The completion test was given prior to the grammaticality judgment test.

\subsection{Scoring and Analysis}

For the DTGJ each item was allocated a score of either 1(if recognized correctly as grammatical or ungrammatical with the correct number of beep sounds)) or 0 (if incorrectly recognized as grammatical or ungrammatical, or wrong number of sounds). The items with no indication of correct/ incorrect, received 0.

Responses to the items of completion tests were scored according to two criteria. When they succeeded to provide the appropriate modal together with the correct form of the verb and correct number of beep sound, they were scored 1 on the item. Items with missing and wrong responses, or wrong number of sounds were scored 0.

To answer the first two research questions two independent sample t-tests were run to compare the groups', performances on the DTGJ and DTCOM tests.

The third research question was answered by running two sets of paired- samples t-tests to examine if the effect of form-focused tasks was retained over time. The first set of t-tests compared the performance of experimental group on pre vs. delayed posttest, and the second set compared that on the post vs. delayed posttests.

\section{Results}

The groups' mean scores on the DTGJ and DTCOM pretests were subject to two independent-samples t-tests. The results revealed that there were no significant difference between the two groups' at the initial stage of the study: GJ: $\mathrm{t}(50)=-1.3, \mathrm{p}=0.2 ; \mathrm{CT}: \mathrm{t}(50)=1.7 \mathrm{p}=0.9$. This indicated that the groups were equivalent in terms of their ability to comprehend and produce the target structure before the experiment; any difference in the result of post and delayed posttest, then, could be attributed to the effect that instruction and practice might make.

\subsection{Production test: proceduralization and retention}

The first research question addressed the proceduralization of production skill as a result of output tasks. 
Mehrnoosh, F., Manijah, Y., \& Daryoush, N.

The two groups' mean scores and standard deviations on the DTCOM pre, post and delayed posttests are presented in Table 2.

Table 2.

Descriptive statistics of the groups on the DTCOMT

\begin{tabular}{lllllll}
\hline Groups & \multicolumn{2}{l}{ Pretest } & \multicolumn{2}{l}{ Posttest } & \multicolumn{2}{c}{ Delayed posttest } \\
\hline & M & SD & M & SD & M & SD \\
Control & 21.9 & 7.8 & 22.3 & 8.1 & 24.6 & 7.4 \\
Output & 16.5 & 8.6 & 57.4 & 16.3 & 62.3 & 20.9 \\
\hline
\end{tabular}

As shown in Table 2, the mean percentage score of the output group on the posttest was markedly better than that of the control group. The figures in the table also indicate that this group's performance on the delayed posttest was better than that on the pretest, and even better than the posttest.

To see whether the difference between the mean scores of the output group and the control group on the completion posttest was significant an independent samples t-test was run. The result showed that the difference was significant: $\mathrm{t}(50)=-.7 .9, \mathrm{p}=0$. The effect size was medium (eta squared $=0.6$ ), indicating that the magnitude of the difference is meaningful.

The third research question was to investigate whether the probable effect of practice on producing the target structure is retained over time. To this end 2 paired-sample t-tests were run.

The first paired-samples t-test compared the experimental group's performance on the pre vs. delayed posttest of timed completion test. The result of the statistical analysis showed that the difference was significant: $t(26)=-14, p=0$. The magnitude of the effect was large (eta squared $=0.9$ ), with the treatment effect explaining up to $90 \%$ of the variance.

Another paired-samples t-test was calculated to compare the mean score of the experimental group on the post vs. delayed posttest of timed completion test. The result revealed that the group's performance on the delayed posttest was not significantly different from that on the posttest: $\mathrm{t}(26)=-1.7, \mathrm{p}=0.1$.

\subsection{Comprehension test: transfer of training and retention}

The second research question addressed the transfer of knowledge or skill over context. The groups' mean scores and standard deviations on the DTGJ pre, post and delayed posttests are presented in Table 3.

\section{Table 3}

Descriptive statistics of the groups on the DTGJT

\begin{tabular}{lllllll}
\hline Groups & Pretest & \multicolumn{3}{c}{ Posttest } & \multicolumn{2}{c}{ Delayed posttest } \\
\hline & $\mathrm{M}$ & $\mathrm{SD}$ & $\mathrm{M}$ & $\mathrm{SD}$ & $\mathrm{M}$ & $\mathrm{SD}$ \\
Control & 45.7 & 10.3 & 49.2 & 8.9 & 43.1 & 12.7 \\
Output & 50 & 16.1 & 72.2 & 11.7 & 74.3 & 9.6 \\
\hline
\end{tabular}

As seen in the table, the mean percentage score of the output group on the posttest exceeded that of the control group. The figures also indicate that the output group's performance on the delayed posttest was still better than that on the pretest and slightly better than the posttest.

To see whether the difference between the mean percentages of the control group and the output group was significant on posttest, an independent samples t-test was run. The result showed that there was a significant difference between the performances of the groups on the TGJ posttest: $t(50)=-7.9, p=0$. The effect size was relatively large (eta squared $=0.6$ ), indicating that the magnitude of the difference is meaningful. 
Proceduralization, transfer of training and retention of knowledge as a result of output practice

The third research question was to investigate whether the probable effect of practice on comprehending the target structure is retained over time. To see if the output group has retained its performance over time two paired samples t-tests were conducted. The first paired-samples t-test compared the group's performance on the pre vs. delayed posttest of DTGJ test. The result of the statistical analysis showed that the difference was significant: $t$ $(26)=-9.5, \mathrm{p}=0$. The magnitude of the effect was large (eta squared $=0.8$ ), with the treatment effect explaining about 80 percent of the variance.

Another paired-samples t-test was calculated to compare the mean score of the group on the post vs. delayed posttest of comprehension. The result revealed that the group's performance on the delayed posttest was not significantly different from that on the posttest: $\mathrm{t}(26)=-15, \mathrm{p}=0.3$, indicating that the experimental group has retained its knowledge over time.

\section{Discussion}

The result of pretests of comprehension and production suggested that both groups had initially limited procedural knowledge on English modals.

The first and the second research questions addressed the extent to which output practice resulted in acquisition of procedural knowledge in production and comprehension of English modals.

The descriptive statistics in Table 2 and 3 and the results of inferential statistics revealed that output practice of different types enabled the participants to integrate the declarative knowledge into their interlanguage system. The results indicate that on both measures of proceduralized knowledge, where the participants' attention is deviated merely from form through time pressure, duality of tasks and irrelevant items, the treatment group were able to process and produce the target structure. As far as the production skill is concerned the experimental group's improvement in their production skill on the posttest was no surprise, since the main purpose of output practice is for the learners to acquire the declarative knowledge and proceduralize it through production tasks. Thus, providing the participants with explicit instruction on the rules and function of English models, followed by a variety of output practice and giving feedback impact significantly on their developing language by helping them attend to the target structure and proceduralize the knowledge. This can be interpreted in light of Swain's Output hypothesis (Swain, 1985).

The hypothesis suggests that output practice facilitates acquisition provided that it allows for processes such as noticing, hypothesis testing syntactic processing and metalinguistic reflection. As hypothesized by Swain (1985, production results in the activation of those cognitive processes that lead to restructuring of the developing system.). In a similar vein, Levelt's (1989) speech production model might help us interpret the results of the present study. One might hypothesize that output practice gives the learners ample opportunities to conceptualize, formulate and articulate materials in contexts where learners are engaged in the tasks which encourage them to convey message relying on their existing linguistic knowledge for language production. The cognitive hypothesis of task-based learning also place a heavy responsibility for learning on the necessity of attention and noticing to the L2 structure (Schmidt, 1983, 2001). In accordance with this, the entrance ticket for the knowledge into the developing linguistic system of the learners is attending and noticing the forms: "Learning, establishing new or modified knowledge, memory, skill, and routines is therefore, largely, and perhaps exclusively, a side effect of attended processing" (Schmidt, 2010: 4). He further distinguished between "noticing" as limited to the conscious registration of attended instances, and "understanding" as a higher level of awareness that includes generalizations across instances.

As to the acquisition of comprehension skill, i.e., transfer of training, it was found that providing learners with a variety of output form-focused practices enables them to acquire the skill to interpret the target structure. In fact introducing a variety of three output-based form-focused tasks as practice in the study has apparently provided opportunities to make form-meaning relationships clear enough to allow the learners to be merely focused, rather than deviated by other requirements of the DTGJ test. The result is compatible with the findings 
Mehrnoosh, F., Manijah, Y., \& Daryoush, N.

in the domain of cognitive and educational psychology where the cognitive psychologists, such as Anderson and Shunn (2000), Schmidt and Bjork (1992), and Speelman and Kirsner (2005) recommended that introducing variation among versions of tasks to be practiced might help the learners generalize their acquired knowledge in the post-training phase to novel situations.

Previous studies (Dekeyser, 1997; DeKeyser and Sokalski, 1996), where the skill was practiced through one input and one output task, showed a partial lack of skill transfer to new contexts. The reason that increased variety during the practice stage of learning brings more general skill, according to Speelman and Kirsner (2005) is efficient adaptation to a task environment. When the learners are faced with no or small variation in tasks, they will merely develop skills to cope with that limited environment. When the practice environment involves variety of tasks, even tasks of the same nature, production task in this study, they learn to cope with this variation. What they do under this circumstance is to rely more on the abstraction of features that are common to many task situations. Therefore, they would develop skills to deal with a variety of situations. Anderson and Shunn (2000) provide an explanation for knowledge transfer which is more related to knowledge-base. They hold that the key to flexible application of knowledge is "understanding", and it is nothing more than having enough knowledge about a concept that can be flexibly used for problem solving involving the concept. This study has, therefore, shown the constructive role of output practice and its variety in transferring the knowledge over context. The DTGJ test employed time pressure and irrelevant items to minimize the possibility of the learners monitoring interpretation merely drawing on their declarative knowledge.

This transfer of knowledge, which is called transfer of training in educational psychology, has been addressed by Schmidt and Bjork (1992). They state that introducing some difficulties for the learner can enhance acquisition as well as retention: " Educators in general and language teachers in particular can induce variation among versions of the tasks to be practiced, with the focus on a criterion of generalizability"(p: 210). Cognitive psychologists have found that for the training of a complex cognitive task, like language learning and use, to be transferred to a new situation, construction of a cognitive structure is inevitable. This enables the learners to recognize particular operations to reach a solution in the new context. Ranzijn ( 1991) and Shapiro and Schmidt ( 1982) (cited in Pass and Van Merrienboer, 1994) pointed out that practice variety is beneficial to the construction of cognitive structures and hence to transfer of acquired skill because it increases the chances that similar features can be identified and that relevant features can be distinguished from irrelevant ones.

As to the retention of procedural knowledge for production of the target structure, the result revealed that six weeks after the last session of practice, the participants still performed better than the time they had not received any practice. The practice and the explicit instruction can explain $90 \%$ of the variance. Comparing the participants' performance on the DTCOM test at the post and delayed post test phase, it was found that the outperformance of the participants did not evade, so that they have not forgotten what they have acquired. Although it is almost impossible to certainly claim whether the knowledge the participants drew upon was implicit/procedural or explicit/declarative, the speed of access to the knowledge benefited the participants after a time span of 6 weeks.

Retention of procedural knowledge for comprehension of the target structure was also shown to persist after a relatively long time. The participants still performed better than the time they had not received any practice. The practice and the explicit instruction can explain $80 \%$ of the variance. Comparing the participants' performance on the DTGJT test at the post and delayed post test phase, it was found that the outperformance of the output group did not fade away, considering the comparably longer retention time of the delayed post test. This result might be interpreted by resorting to what is called depth of processing. Anderson (2000) cites Craik and Lockhart (1972) who argued that what is critical for the information not to be forgotten is not how long the information is rehearsed but rather the depth to which it is processed. Accordingly, thanks to the communicative nature of tasks the information is rehearsed in the practice phase in a deep and meaningful way. Deep and meaningful processing of information, then, leads to a long-term memory trace (Anderson, 2000). 
Proceduralization, transfer of training and retention of knowledge as a result of output practice

Another explanation for the maintenance of comprehension ability over time rests on another focal concept in ACT-R theory of skill acquisition. To describe the memory trace, this theory relies on the concept of "activation" which determines the probability of access to memory and the speed with the memory is accessed. The more a memory is practiced, the stronger it becomes and the more successfully it is retrieved.

Overall, the results of this study suggest that, when institutional limitations do not allow for providing practice of different nature which require different cognitive processes, and definitely requires more time and energy on the part of language teachers to prepare them, introduction of one type of practice might help learners proceduralize the explicit declarative knowledge and transfer that knowledge to relatively dissimilar context of retention test, provided that the teacher introduces variety onto the output tasks.

\section{Conclusion}

The present results confirm that production practices develop production skill as well as comprehension skill.

Although the results of this study, and other studies of the same nature, might not guarantee that the knowledge the participants drew on was surely proceduralized, the results confirms what Dekeyser and Juffs (2005) stated about the speeded availability of explicitly acquired knowledge which can be viewed as precious. This knowledge, if not the ultimate goal of language acquisition, can be an intermediate goal on the road to spontaneous language use. Although the real goal of language learning is effortless automatic use of language, automatic use by itself does not exclude the possibility of explicit knowledge accessibility (Dekeyser, 2007). Considering the skill-specificity/generality of knowledge in the skill-acquisition theory, availability of speeded explicit declarative knowledge, or at least partially acquired proceduralized knowledge can enable learners to generalize it to unfamiliar contexts. The pedagogical implication of the study is that besides input practices, there seems to be other options, decided in terms of institutional ecological situations, which can help learners acquire comprehension skills .However, due to some limitations, mentioned bellow, the generalizability of the results requires cautions. Another implication is that at least for structures like modals, for which the mapping of formmeaning relationship is not evident, practices of the same type would lead into a relatively more stable effect.

It should be pointed out that several limitations existed in the process of running the study. To measure the effect of practice on the procedural knowledge, designing instruments which measure the knowledge in an on-line, real communication is felt to be inevitable. However, some structures are less amenable to these types of test; designing a test in which a target structure, like modals, is elicited to occur in obligatory context was, if not impossible, very difficult.

\section{References}

Anderson, J. R. (1983). The architecture of cognition. Cambridge, MA: Harvard University Press.

Anderson, J. R. (Ed.) (1993). Rules of the mind. Hillsdale, NJ: Erlbaum.

Anderson, J. R. (2000). Cognitive psychology and its implications. New York: Worth Publishers

Anderson, J. R., Fincham, J. M., \& Douglass. S. (1999). The role of examples and rules in the acquisition of cognitive skills. Journal of Experimental Psychology: learning, memory and cognition, 23. 932-945. http://dx.doi.org/10.1037/0278-7393.23.4.932

Anderson, J. R., \& Shunn, C. D. (2000). Implications of the ACT-R learning theory: No magic bullets. In the Glasser Advances in instructional psychology Vol.5. Mahwah, NJ: Erlbaum.

Carlson, R. A. (2003). Skill learning. In L. Nadel ( Ed.), Encyclopedia of cognitive science, 4 ( pp. 36-42).London: Macmillan.

Cook, G. (2010). Translation in language teaching. Oxford" Oxford University press

Craik, F. I. M., \& and Lockhart, R. S. (1972). Levels of processing: A framework for memory research. Journal of verbal learning and verbal behavior, 11,671-684. http://dx.doi.org/10.1016/S0022-5371(72)80001-X 
Mehrnoosh, F., Manijah, Y., \& Daryoush, N.

De Graaff , R. (1997). The eXperanto experiment: Effects of explicit instruction on second language acquisition. Studies in second language acquisition. 19, 249-297. http://dx.doi.org/10.1017/S0272263197002064

Dekeyser, R.M. (1995). Learning second language grammar rules: “An experiment with a miniature linguistic system. Studies in second language acquisition. 17, 379-410. http://dx.doi.org/10.1017/S027226310001425X

DeKeyser, R. (1997). Beyond explicit rule learning: Automatizing second language morphosyntax. Studies in Second Language Acquisition, 19(2), 195-221. http://dx.doi.org/10.1017/S0272263197002040

DeKeyser, R. M. (1998). Beyond focus on form: Cognitive perspectives on learning and practicing second language grammar. In Doughty, C. and J. Williams (Eds.). Focus on Form in Classroom Second Language Acquisition (pp. 42- 63). Cambridge: Cambridge University Press.

Dekeyser, R. M. (2007). Practice in a second language: Perspectives from applied linguistics and cognitive psychology. Cambridge: Cambridge University press.

Dekeyser, C. (2009). Cognitive-Psychological Processes in Second Language Learning. In M.H. Long and C.J. Doughty (Eds.). The handbook of language teaching, (pp.119-138). Wiley- Blackwell. http://dx.doi.org/10.1002/9781444315783.ch8

DeKeyser, R. M., \& Juffs, A. (2005). Cognitive considerations in L2 learning. In E. Hinkel (Ed.), Handbook of Research in Second Language Teaching and Learning (pp. 437-454). Mahvah, NJ. London: Lawrence Erlbaum associates

DeKeyser, R. M., Salaberry, R., Robinson, P., \& Harrington, M. (2002). What gets processed in processing instruction? A commentary on Bill VanPatten's "Processing instruction: An update." Language Learning, 52(4), 805-823. http://dx.doi.org/10.1111/1467-9922.00204

DeKeyser, R., \& Sokalski, K. (1996). The differential role of comprehension and production practice. Language Learning, 46, 4, 613-642.http://dx.doi.org/10.1111/j.1467-1770.1996.tb01354.x

Doughty, C., \& Williams, J. (Eds.) (1998). Focus on form in classroom second language acquisition. Cambridge, UK: Cambridge University Press.

Driskell, J. E., Willis, R. P., \& Cooper, C. (1992). Effect of overlearning on retention. Journal of Applied Psychology, 77, 615-622.http://dx.doi.org/10.1037/0021-9010.77.5.615

Ellis, R. (1992). Second language acquisition and language pedagogy. Clevedon, UK: Multilingual Matters

Ellis, R. (1993). Second language acquisition and the structural syllabus. TESOL Quarterly. 27, 91-113. http://dx.doi.org/10.2307/3586953

Ellis, R. (2002). Does form=focused instruction affect the acquisition of implicit knowledge? Studies in second language acquisition, 24(2), 223-236. http://dx.doi.org/10.1017/S0272263102002073

Ellis, R. (2003). Task-based Language Learning and Teaching. Oxford: Oxford University Press.

Ellis, R. (2009).the measurement of implicit and explicit knowledge in Ellis, Loewen, Elder, Erlam, Philp and Reinders (Eds.) Implicit and Explicit Knowledge in Second Language Learning,Testing and Teaching. Bristol, Buffalo, Totonto. Multilingual Matters.

Erricson, K.A., Krampe, R.T., \& Tesch- Romer, C. (1993). The role of deliberate practice in the acquisition of expert performance. American psychologist, 100, 363-406.

Izumi, S. (2002). Output, input enhancement, and the noticing hypothesis: An experimental study on ESL relativization. Studies in Second Language Acquisition, 24(4), 541-577. http://dx.doi.org/10.1017/S0272263102004023

Izumi, S. (2003). Comprehension and production processes in second language learning: In search of the psycholinguistic rationale of the output hypothesis. Applied Linguistics, 24(2), 168-196. http://dx.doi.org/10.1093/applin/24.2.168

Izumi, S. \& Bigelow, M. (2000). Does output promote noticing and second language acquisition? TESOL Quarterly, 34, 239-278. http://dx.doi.org/10.2307/3587952

Levelt, W. (1989). Speaking: From intention to articulation. Cambridge, MA: Newbury House.

Muranoi, H. (2007). Output practice in the L2 classroom. In C. Dekeyser (Ed). Practice in a second language: Perspectives from applied linguistics and cognitive psychology. (p.52-84). Cambridge: Cambridge University press. 
Proceduralization, transfer of training and retention of knowledge as a result of output practice

Nagata, N. (1998a). Input vs., output practice in educational software for second language acquisition, Language learning and technology, 1(2), 23-40.

Nagata, N. (1998b). The relative effectiveness of production and comprehension practice in second language acquisition. Computer assisted language learning, 11(2), 153-177. http://dx.doi.org/10.1076/call.11.2.153.5686

Qin, J. (2008). The effect of processing instruction and dictogloss tasks on acquisition of the English passive voice. Language teaching research, 12(1), 61-82. http://dx.doi.org/10.1177/1362168807084494

Ranzijn, F.J.A. (1991). The number of video examples and the dispersion of examples as instructional design variables in teaching concepts. Journal of Experimental Education, 59, 320- 330

Reinders, H. (2009). Learner uptake and acquisition in three grammar-oriented production activities. Language Teaching Research, 13(2), 201-222. http://dx.doi.org/10.1177/1362168809103449

Schmidt, R. (1983). 'Interaction, acculturation and the acquisition of communication competence' in M. Wolfson and E. Judd (Eds). Sociolinguistics and second language Acquisition. Rowley, MA: Newbury House.

Schmidt, R. (2001). 'Attention'. In P. Robinson (Ed.), Cognition and second language instruction. Cambridge: Cambridge University Press. http://dx.doi.org/10.1017/CBO9781139524780.003

Schmidt, R. (2010). Attention, awareness, and individual differences in language learning. In W. M. Chan, S. Chi, K. N. Cin, J. Istanto, M. Nagami, J. W. Sew, T. Suthiwan, \& I. Walker, Proceedings of CLaSIC 2010, Singapore, Centre for language studies.

Schmidt, R. A., \& Bjork, R. A. (1992). New conceptualizations of practice: Common principles in three paradigms suggest new concepts for training. Psychological Science, 3(4), 207-217. http://dx.doi.org/10.1111/j.1467-9280.1992.tb00029.x

Serrano, R. \& Munoz, C. (2007).Same hours, different time distribution: Any difference in EFL? System, 35, 305-321. http://dx.doi.org/10.1016/j.system.2007.02.001

Sharwood Smith, M. (1981). Consciousness-raising and the second language learner. Applied Linguistics, 2 , 159-169. http://dx.doi.org/10.1093/applin/2.2.159

Speelman, C.P. \& Kirsner,K. (2005). Beyond the Learning Curve: The construction of mind. Oxford. Oxford University Press. http://dx.doi.org/10.1093/acprof:oso/9780198570417.001.0001

VanPatten, B. (1996). Input processing and grammar instruction: Theory and research. Norwood,NJ: Ablex.

VanPatten, B. (2003). From input to output: A teacher's guide to second language acquisition. New York: McGraw-Hill.

Wajnryb, R. (1990). Grammar dictation. Oxford: Oxford University Press. 


\section{Appendix A}

Samples of tasks in the output group

\section{Dictogloss}

My friend Dona cannot say "no". If another student asks her, "May I ask for your pen?" she always says, ' Of course, you can, and hands it over, even when she only has one pen and it means she cannot do her work. After I heard she did that one day, I told her that she can say 'Sorry, but you cannot, because I only have one pen' in reply, she said, 'But how are they able to do their work without a pen?' I knew that I could have tried to answer that question, but somewhat I did not think I had the ability to change how she behaved, no matter what I said.

\section{Test reconstruction task}

My sister lived in Montana, and when I was visiting her, we would go on weeklong backpacking trips in the mountain. Every morning we woke up to the sound singing birds. During the day, we used to hike through woods and along mountain streams. Often we saw deer. Once we used to see a bear, but it went off the opposite direction.

\section{Corrected close translation}

$$
\begin{aligned}
& \text { املت درست كردن كار آسانى است. مجبور نيسنيد آثنبز ماهرى باثيد تا املت درست كنيد. در اينجا شما را باجند نكته آشنا مرحله از بخت املت } \\
& \text { آثنا مى كنيم. } \\
& \text { اول جند تخم مرغ غر را در يك كاسه بشكنيد. اينكار رابا دقت انجام دهيد نبايد اصلا يوست تخم مر غ داخل املت باشد. }
\end{aligned}
$$

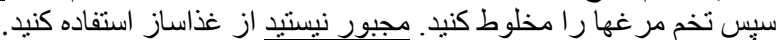

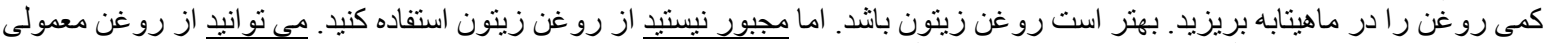

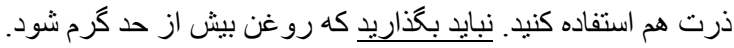

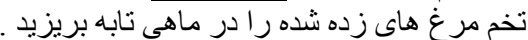

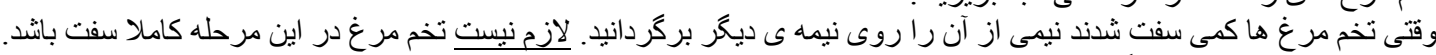

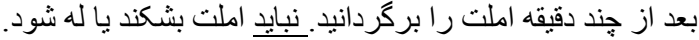

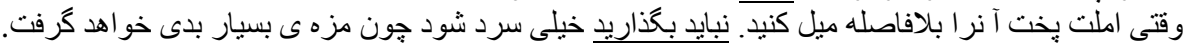

\section{Appendix B}

\section{Dual Task Timed GJ Test sample of items}

1. A- Can't you find that newspaper? B- I am not sure, but, I think someone might have thrown it away. --

2. A- Has the car broken down? B- Well, we may run out of petrol. That's why it doesn't run anymore. --

3. Daughter: I sent my best friend a birthday present, but she never responded or thanked me. Mother: I guess, that must get lost in the mail.

\section{Dual Task Timed Completion Test sample of items}

1. A: Last night. I heard someone was playing a very difficult piece on the piano. B: I --------------(not be) John. He does not know how to play.

2. A: Oops! I spilled coffee on my shirt. B: You (wash) under hot water before the stain sets.

3. Amy's grammar book is not on her desk. Where is it? B: I don't know. It -(be) in her backpack. 